\title{
ENHANCING EXECUTIVE FUNCTIONS IN PRESCHOOLERS: TECHNOLOGIES YES OR NOT?
}

\author{
Sabrina Panesi and Lucia Ferlino \\ Institute for Educational Technology of the CNR, Via de Marini, 6, Genoa, Italy
}

\begin{abstract}
Training to improve executive functions in pre-schoolers is a hot topic since it's very important to enhance these cognitive abilities starting from a young age. Executive functions are associated with and predictive of other cognitive and social components. In literature, several researches support the idea that training with technological tools can provide more benefits, while others underline the importance of training with analogue materials. This paper highlights strengths and weaknesses of these two approaches and stimulates reflection on further research.
\end{abstract}

\section{KEYWORDS}

Executive Functions, Cognitive Training, Preschoolers, Educational Technologies

\section{INTRODUCTION}

Executive Functions (EFs) is an umbrella term that refers to a family of adaptive, goal-directed, top-down mental processes that are activated to focus and pay attention in those cases where an automatic response would be insufficient (e.g., Burgess \& Simons, 2005). In adults, Miyake and colleagues (2000; 2012) argued that EFs is composed of partially dissociable components that share an underlying process. They focused on three core EFs components: inhibition, the ability to suppress task-irrelevant cognitive processing and ignore salient yet irrelevant features of the situation (Miyake et al., 2000), shifting, the ability to switch between different operations or levels of processing (Miyake et al., 2000), and updating, the ability to encode, hold and monitor incoming information in working memory replacing information that is no longer relevant with new information (Panesi \& Morra, 2017). Furthermore, Miyake and colleagues $(2000 ; 2012)$ suggested the possibility that all EFs rely to some extent on working memory (WM), i.e. the simultaneous maintenance and manipulation of information. Actually, if on the one hand there is an agreement about the structure of EFs in adults, on the other hand the structure of EFs and their development is widely debated in developmental research, in particular referring to pre-schoolers (Garon, Bryson, \& Smith, 2008; Morra, Panesi, Traverso, \& Usai, 2018; Panesi \& Morra, 2020). Recent studies involving pre-schoolers with typical and atypical development found that EFs were associated with other cognitive abilities, such as representational systems (Panesi \& Morra, 2018), and predictive of future academic outcomes (Allan \& Lonigan, 2011), social cognition (Denham, Bassett, Zinsser, Wyatt et al., 2014), and self-regulation (Sokol, Muller, 2007). It is therefore fundamental to promote EFs with specific training, starting from a young age. For this reason, in literature, there is an increasing interest in investigating the effect of training to promote EFs in pre-schoolers, but while several researches claim that training with technologies can provide more benefits, others are in favour of training with analogue playful materials. The present paper has the aim to stimulate a reflection about these two lines of thought highlighting strengths and weaknesses of both (Figure 1).

\section{ENHANCING EFs WITH TECHNOLOGIES IN PRESCHOOLERS}

In the digital era, technologies are very motivating and familiar to digital natives, so they can represent a "powerful" tool to involve young children. In the context of cognitive training, the mostly used technological tools to enhance EFs in pre-schoolers are software (e.g., Thorrell et al., 2009), apps (e.g. Panesi, Freina 
\& Ferlino, 2020), and educational robotics (e.g. Di Lieto et al., 2020). Initially, technological tools, in particular software, were used to enhance EFs in a clinical context, to promote cognitive abilities in children with some deficit in EFs, and these interventions involved one child at a time, usually with a specific computer software. Recent research highlighted the importance to improve EFs in all children, also those with typical development, starting from preschool years and several approaches to training EFs in the educational context have been developed. Among these, some are based on the use of technologies, such as educational robotics (Di Lieto et al., 2020) or apps (Panesi, Ferlino \& Podestà, 2020), with little groups of children with typical and atypical development, within the school environment. Interventions based on digital apps have the double advantage of allowing task difficulty to automatically adapt to the child's performance and permitting to focus on the specific EFs components. On the other hand, such applications are, for the most part, self-contained training applications: they are seldom generalizable to daily life activities and are resource consuming, involving individual exercises and extensive teacher training to be correctly deployed (e.g. Thorrell et al., 2009).

\section{ENHANCING EFs WITHOUT TECHNOLOGIES IN PRESCHOOLERS}

Training programs without technologies are based on low-cost paper-and-pencil activities and are more widespread in the educational context (e.g., Traverso et al., 2015). Unlike training with technologies, these are more generalizable and ecological to daily life activities. On the other hand, they also present some weaknesses. First, with these kind of training, the customization of activities is difficult, when not impossible. Furthermore, it is more difficult to focus on the specific EFs components. Finally, they are not in line with the pervasive drive for digitally-based school innovations.

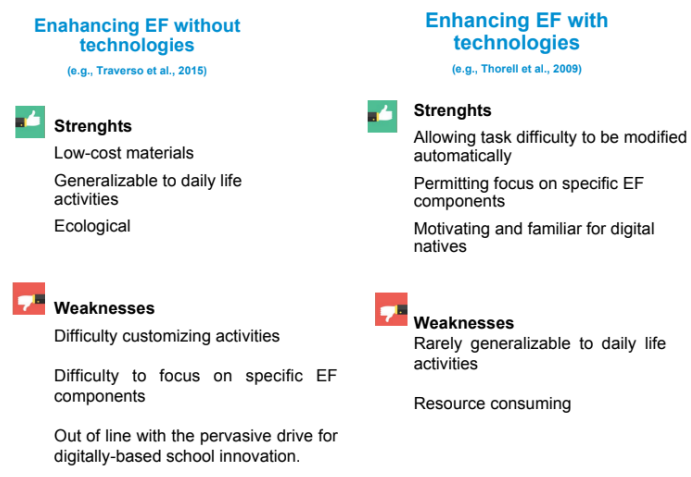

Figure 1. Training with and without technologies to enhance EFs: strengths and weaknesses

\section{COMBINING TRAINING WITH AND WITHOUT TECHNOLOGIES}

Integrating digital approaches with more traditional, low-tech activities could bring added advantages to foster the development of EFs in pre-schoolers. In literature, Röthlisberger and colleagues (2012) proposed mixed individual and group training based on different types of activities and games. Their intervention focused on the basic components of EFs and represents a good tradeoff between individualized computer-based interventions and large-group curricular interventions. In line with Röthlisberger and colleagues (2012), Panesi, Ferlino \& Podestà (2019) present a training intervention designed to promote EFs in preschoolers with typical and atypical development within the educational context. The intervention combines the use of technology (through specific apps) along with analogical materials. These studies open to a new field of research and provide practical implications in both educational and clinical contexts, allowing teachers and clinicians to offer children both individualized and collective activities by exploiting the potential of interventions with analog and digital tools. 


\section{CONCLUSION}

In sum, according to the literature analysis, both types of training have some strengths and some weaknesses. Therefore, in our opinion, further research is needed, aiming at the integration of digital approaches with the more traditional, low-tech activities, oriented to the definition of specific training paths, tailored to each child, taking into account their environment with the aim of fostering EFs in young digital natives.

\section{ACKNOWLEDGEMENT}

We would like to thank Laura Freina for reviewing the English of the manuscript.

\section{REFERENCES}

Allan, N., Lonigan, C., 2014. Exploring dimensionality of effortful control using hot and cool tasks in a sample of preschool children. Journal of Experimental Child Psychology, Vol. 122, pp. 33-47.

Denham, S.A., Bassett, H.H., Zinsser, K., Wyatt, T.M., 2014. How preschoolers' social-emotional learning predicts their early school success: Developing theory promoting, competency based assessments. Infant and Child Development, Vol 23, no. 4, pp. 426-454.

Di Lieto, M. C., Castro, E., Pecini, C., Inguaggiato, E., Cecchi, F., Dario, P., Cioni, G., Sgandurra, G., 2020. Improving Executive Functions at School in Children With Special Needs by Educational Robotics. Frontiers in psychology, 10, 2813.

Garon, N., Bryson, S. E., \& Smith, I. M., 2008. Executive function in preschoolers: A review using an integrative framework. Psychological Bulletin, Vol. 134, No.1, pp. 31-60.

Miyake, A., \& Friedman, N. P., 2012. The nature and organization of individual differences in executive functions: four general conclusions. Current Directions in Psychological Science, Vol.21, No.1, pp. 8-14.

Miyake, A., Friedman, N. P., Emerson, M.J., Witzki, A.H., Howerter A., Wager, T.D., 2000. The unity and diversity of executive functions and their contributions to complex "Frontal Lobe" tasks: a latent variable analysis. Cognitive Psychology, Vol.41, No. 1, pp. 49-100.

Morra, S., Panesi, S., Traverso, L., Usai, M. C., 2018. Which tasks measure what? Reflections on executive function development and a commentary on Podjarny, Kamawar, and Andrews (2017). Journal of Experimental Child Psychology. Vol. 167, pp. 246-258.

Panesi, S., Ferlino, L., Podestà, M., 2020. Apps and collective playful activities to foster executive functions in preschoolers following an inclusive approach: a case study. Proceedings of EDULEARN20 12th annual International Conference on Education and New Learning Technologies.

Panesi, S., Freina, L., Ferlino, L., 2020. A Kit of apps to improve and assess executive functions and working memory capacity in preschoolers. 17th International Conference on Cognition and Exploratory Learning in Digital Age (CELDA 2020), pp. 331-334

Panesi, S., Morra, S., 2017. La casetta magica. Uno strumento per indagare l'aggiornamento (updating) della memoria di lavoro in età prescolare [The magic house. A new measure of updating for preschoolers]. Psicologia Clinica dello Sviluppo, Vol. 21, No.3, pp.443-462.

Panesi, S., Morra, S., 2018. Relationships between the early development of drawing and language: The role of executive functions and working memory. The Open Psychology Journal, 11(1).

Panesi, S., Morra, S., 2020. Executive functions and mental attentional capacity in preschoolers. Journal of Cognition and Development, Vol.21, No.1, pp. 72-91.

Röthlisberger, M. Neuenschwander, R. Cimeli, P. Michel, E., Roebers, C.M. (2012).Improving executive functions in 5-and 6-year-olds: Evaluation of a small group intervention in prekindergarten and kindergarten children. Infant and Child Development, Vol. 21, no.4, pp. 411-429

Sokol, B.W., Müller, U. 2007. The development of self-regulation: Toward the integration of cognition and emotion [Editorial]. Cognitive Development, Vol. 22, no. 4, pp. 401-405.

Thorell, L.B., Lindqvist, S. Bergman Nutley, S., Bohlin, G., \& Klingberg, T., 2009. Training and transfer effects of executive functions in preschool children. Developmental science, Vol. 12, No.1, pp.106-113.

Traverso, L., Viterbori, P., \& Usai, M. C., 2015. Improving executive function in childhood: evaluation of a training intervention for 5-year-old children. Frontiers in psychology, 6, 525. 